\title{
Gestational weight gain in overweight and obese women enrolled in a healthy lifestyle and eating habits program
}

\section{E. Petrella, M. Malavolti, V. Bertarini, L. Pignatti, I. Neri, N. C. Battistini \& F. Facchinetti}

To cite this article: E. Petrella, M. Malavolti, V. Bertarini, L. Pignatti, I. Neri, N. C. Battistini \& F. Facchinetti (2014) Gestational weight gain in overweight and obese women enrolled in a healthy lifestyle and eating habits program, The Journal of Maternal-Fetal \& Neonatal Medicine, 27:13, 1348-1352, DOI: 10.3109/14767058.2013.858318

To link to this article: http://dx.doi.org/10.3109/14767058.2013.858318

Accepted author version posted online: 01 Nov 2013.

Published online: 25 Nov 2013.

Submit your article to this journal $₫$

Џلll Article views: 366

Q View related articles $ᄃ$

View Crossmark data ־

Citing articles: 1 View citing articles $₫$ 


\title{
Gestational weight gain in overweight and obese women enrolled in a healthy lifestyle and eating habits program
}

\author{
E. Petrella ${ }^{1}$, M. Malavolti ${ }^{2}$, V. Bertarini ${ }^{2}$, L. Pignatti $^{1}$, I. Neri ${ }^{1}$, N. C. Battistini ${ }^{2}$, and F. Facchinetti ${ }^{1}$ \\ ${ }^{1}$ Mother-Infant Department, University of Modena and Reggio Emilia, Modena, Italy and ${ }^{2}$ Clinical Diagnostic Medicine and Public Health \\ Department, University of Modena and Reggio Emilia, Modena, Italy
}

\begin{abstract}
Objectives: To determine whether changes in lifestyle in women with BMI $>25$ could decrease gestational weight gain and unfavorable pregnancy outcomes.

Methods: Women with $\mathrm{BMI}>25$ were randomized at 1 st trimester to no intervention or a Therapeutic Lifestyle Changes (TLC) Program including diet (overweight: $1700 \mathrm{kcal} /$ day, obese: $1800 \mathrm{kcal} /$ day) and mild physical activity ( $30 \mathrm{~min} /$ day, 3 times/week). At baseline and at the 36th week women filled-in a Food Frequency Questionnaire. Outcomes: gestational weight gain, gestational diabetes mellitus, gestational hypertension, preterm delivery. Data stratified by BMI categories.

Results: Socio-demographic features were similar between groups (TLC: 33 cases, Controls: 28 cases). At term, gestational weight gain in obese women randomized to TLC group was lower $(6.7 \pm 4.3 \mathrm{~kg})$ versus controls ( $10.1 \pm 5.6 \mathrm{~kg}, p=0.047)$. Gestational diabetes mellitus, gestational hypertension and preterm delivery were also significantly lower. TLC was an independent factor in preventing gestational weight gain, gestational diabetes mellitus, gestational hypertension. Significant changes in eating habits occurred in the TLC group, which increased the number of snacks, the intake of fruits-vegetables and decreased the consumption of sugar.

Conclusions: A caloric restriction associated to changes in eating behavior and constant physical activity, is able to reduce gestational weight gain and related pregnancy complications in obese women.
\end{abstract}

\section{Introduction}

Within the European Union, over half of the adult population are classed as being overweight or obese according to their body mass index (BMI) [1]. Considering the rising maternal age at first pregnancy, high pre-pregnancy BMI is frequently encountered in the practice of obstetrics. Obesity and excessive weight gain are associated with many unfavorable maternal-neonatal outcomes, both short and long term [2-5].

For many years, attention was focused on obesity during pregnancy as a risk factor for gestational diabetes mellitus and hypertensive disorders. Recently, a study found [6] that a high pre-pregnancy BMI is associated with adverse pregnancy outcomes independent of glucose tolerance. Thus, the focus has now shifted from high pre-pregnancy BMI to interventions to limit excessive weight gain at term.

All authors have read and approved the manuscript. This manuscript has not been submitted and will not be submitted for review or publication anywhere else. The authors agree to shorten the manuscript if necessary to increase the likelihood of acceptance. The authors wish for an open review.

Address for correspondence: Facchinetti Fabio, MD, Mother-Infant Department, Policlinico Hospital - University of Modena and ReggioEmilia, Via del Pozzo 71, 41124 Modena, Italy. Tel: 00390594222512. E-mail: fabio.facchinetti@unimore.it

\section{Keywords}

Diet, gestational diabetes, obesity, physical activity, unfavorable outcomes

\section{History}

Received 22 July 2013

Revised 4 October 2013

Accepted 20 October 2013

Published online 25 November 2013
The Institute of Medicine (IOM) (2009) updated guidelines for the ideal weight gain at term according to pre-gestational BMI category while emphasizing the importance of physical activity in addition to diet for weight control [7].

Despite both American College of Obstetricians and Gynecologists and American College of Sports Medicine $[8,9]$ recommend a certain amount of physical activity in pregnant women, several studies on gestational weight gain both in the US and Europe indicate that just a small sample of women remain within the IOM recommendations $[4,10,11]$. Moreover, according to the most recent Cochrane review [12], interventions to prevent and/or limit excessive weight gain have not been adequately evaluated.

This study aims to determine whether changes in lifestyle can prevent excessive weight gain and reduce unfavorable maternal-fetal outcomes.

\section{Methods}

\section{Study design}

This study is a prospective, randomized controlled trial. It was approved by the Local Ethics Committee. All volunteers gave written informed consent.

Pregnant women recruited from antenatal clinics with pre-pregnancy $\mathrm{BMI} \geq 25 \mathrm{~kg} / \mathrm{m}^{2}$, age $>18$ years and single 
pregnancy were enrolled between April and October 2011 during their 12th week at the Obstetric Unit, Mother-Infant Dept. of Policlinico Hospital - University of Modena.

Exclusion criteria: twin pregnancy, chronic diseases (i.e. diabetes mellitus, chronic hypertension, untreated thyroid diseases), gestational diabetes mellitus in previous pregnancies, smoking during pregnancy, previous bariatric surgery, women who just engaged in regular physical activity, dietary supplements or herbal products known to affect body weight, other medical conditions that might affect body weight, and plans to deliver outside our Birth Center.

At the first visit, an accurate obstetric history, family history and personal history were collected for the assessment of exclusion criteria.

Eligible women were randomly assigned to no intervention (Controls) or to Therapeutic Lifestyle Changes Program (TLC group). Randomization list was obtained by using a computer-generated random allocation in blocks of three. The numbers were sealed in numbered white envelopes. After eligibility assessment, the midwife open the next envelop. Due to study design, both gynecologist and dietitian knew the allocation of the patient.

Weight (using the Bioelectrical Impedance Analysis Tanita, Tokyo, Japan) and height (using a stadiometer) were measured at enrollment and at delivery. BMI was calculated as Weight $(\mathrm{kg}) / \mathrm{Height}\left(\mathrm{m}^{2}\right)$.

Every subject received cares in the Antenatal Clinics of Modena National Health System: two ultrasound examinations and at least four antenatal obstetric evaluations until term. However, the referral gynecologists knew the allocated arm.

The overall cohort has been submitted to fasting glucose assessment until the 12th week, than to $75-\mathrm{g}-2 \mathrm{~h}$ Oral Glucose Tolerance Test (OGTT) between 16th-18th or 24th-28th week as recommend. The diagnosis of gestational diabetes mellitus was made for glucose values exceeding the normal cut-off, according to the American Diabetes Association [13]. When 75 -g-2 h OGTT was positive, women referred to other health care specialists for diet and/or insulin treatment.

Women randomized to the Therapeutic Lifestyle Changes group were scheduled to have a specific follow-up for adherence to the program at 16th, 20th, 28th and 36th week. Moreover, at baseline and at 36th week, each subject enrolled in the Therapeutic Lifestyle Changes group had to complete a Food Frequency Questionnaire (FFQ) to identify any change in eating habits. The development, reproducibility and validity of the Food Frequency Questionnaire were described in previous studies [14-16]. After counseling, the Control group attended their regularly scheduled visits until delivery by the obstetricians in charge.

The primary outcome was the rate of women with excessive weight gain over the IOM recommended ranges for each BMI category. Secondary outcome were diagnoses of gestational diabetes mellitus [13], gestational hypertension [17] and rate of preterm delivery. Data were stratified by BMI categories (overweight and obesity).

Obstetric records were reviewed after delivery to obtain information about maternal-fetal complications during pregnancy and/or delivery.

\section{Intervention}

The Control group received a simple nutritional booklet about lifestyle, in agreement with Italian Guidelines for a healthy diet during pregnancy $[18,19]$.

The Therapeutic Lifestyle Changes group diet comprised $1500 \mathrm{kcal} /$ day and consisted of three main meals and three snacks. In view of the physical activity program, the dietitian added an amount of $200 \mathrm{kcal} /$ day for obese or $300 \mathrm{kcal} / \mathrm{day}$ for overweight women [20].

The Therapeutic Lifestyle Changes diet was introduced at randomization in the presence of both a gynecologist and a dietitian and further detailed through a one-hour counseling session about the appropriate gestational weight gain at term (for each BMI category) for preventing unfavorable outcomes related toexcessive weight gain. The primary focus of the dietary intervention was decreasing high-Glicemic Index foods consumption and substituting them with healthier alternatives; the second goal was to redistribute the number of meals along the day and include the last snack two hours after dinner to avoid hypoglycemia during the night.

The diet had a target macronutrient composition of 55\% carbohydrate $(80 \%$ complex with low-Glycemic Index and $20 \%$ simplex), $20 \%$ protein (50\% animal and $50 \%$ vegetable) and $25 \%$ fat (12\% mono-insatured, $7 \%$ poli-insatured and $6 \%$ satured) with moderately low saturated fat levels. The daily calories were divided into small frequent meals to avoid ketonuria and acidosis, which often occurs due to prolonged fasting. The daily intake of carbohydrates was at least of $225 \mathrm{~g} /$ day (the minimum daily intake to prevent ketosis is $180 \mathrm{~g} /$ day) [21]. The rate of ketonuria was assessed with urine exams at enrollment, 24-27 and 33-37 weeks.

The exercise intervention was focused on developing a more active lifestyle. The recommended exercise prescription for pregnant women is generally consistent with recommendations for the general population [9]. All participants were advised to participate in $30 \mathrm{~min}$ of moderate intensity activity at least 3 days a week. Subjects wore a pedometer (Omron Walking Style III HJ-203-EK, Omron Healthcare Co., Kyoto, Japan) on a belt at the back of their waist during each walking session for the assessment of the adherence to the physical activity program. Women were told to consider using the "talk test" (being able to maintain a conversation during activity) to monitor exercise intensity.

\section{Statistical analysis}

According to previous unpublished observations we expected that at least $2 / 3$ of the population undergo a excessive weight gain in pregnancy. The power of the study was calculated with the hypothesis that intervention was able to reduce by $50 \%$ of the rate of women exceeding IOM recommendation. Thus, 30 women/arm would be enough to observe a statistical significant difference.

To compare gestational weight gain and birth weight, Student's $t$-test was employed. A Chi-squared test was used for categorical variables (percentage of women whose gestational weight gain remained within the IOM recommendations, gestational diabetes mellitus and/or pregnancy-induced hypertension diagnosis as well as rate of preterm birth). For 
demographic variables, we used frequencies and Student's $t$-test comparisons.

A logistic regression was used to evaluate the effect of intervention with respect to confounding variables (age, BMI, ethnicity, family history of diabetes) on both gestational diabetes mellitus and hypertensive disorders.

Wilcoxon's signed rank test was used for non-parametric values (Food Frequency Questionnaire analysis).

Data are reported as the mean \pm SD or numbers with $\%$ in brackets or the median with interquartile ranges (IQ 25-75). We considered $p$ values less than 0.05 as the threshold for statistical significance. The data were analyzed with SPSS Statistics software v 19.0 (SPSS Statistics software v 19.0, IBM Corp. in Armonk, NY, USA).

\section{Results}

Two women randomized to Controls later withdrew their consent for the study. Therefore, the remnant participants were 33 in the Therapeutic Lifestyle Changes group and 28 in the Controls.

At 18th week none tested positive at 75 -g-2h OGTT. Among those testing positive at 24-26th week and thus referred to diabetologist, none received insulin. Neither relative/absolute contraindications to aerobic exercise nor warning signs to terminate exercise were observed in Therapeutic Lifestyle Changes group [8]. As planned, all women delivered in our Birth Centre ( $>3000$ births/year).

The socio-demographic characteristics of participants are summarized in Table 1. Morbidly obese women were equally distributed (Therapeutic Lifestyle Changes group: 3; Control group: 4).

Overall, the gestational weight gain at delivery was higher in Controls (Table 2), exceeding the recommendations in $17 / 28$ cases $(60 \%)$, while this occurred only in $11 / 33(33 \%)$ cases in Therapeutic Lifestyle Changes group. However, upon stratifying for BMI, a significantly lower gestational weight gain was found in obese women randomized to the Therapeutic Lifestyle Changes group (Table 2), while no significant differences were found in overweight women.

The incidence of gestational diabetes mellitus was significantly lower in the therapeutic lifestyle changes than in the control group (Table 2). Similarly, the incidence of gestational diabetes mellitus, hypertensive disorders in pregnancy and the rate of preterm delivery were also lower in the Therapeutic Lifestyle Changes group (Table 2). The whole preterm delivery were late pre-term births: three spontaneous deliveries, two after induction of labor and five cesarean deliveries for medical indications.

A logistic regression analysis confirmed that therapeutic lifestyle changes intervention was an independent factor for preventing excessive weight gain $(R$-square $=0.14$; $p=0.014)$, adjusting for Caucasian ethnicity $(p=0.111)$, age $<35$ years $(p=0.345)$, active job $(p=0.520)$, high school education $(p=0.611)$ and $\mathrm{BMI} \leq 30(p=0.981)$.

Moreover therapeutic lifestyle changes intervention was an independent factor for preventing gestational diabetes mellitus ( $R$-square $=0.15 ; p=0.014)$ after adjusting for BMI $\leq 30(\mathrm{p}=0.38)$, age $\leq 35$ years $(p=0.36)$, Caucasian ethnicity $(p=0.58)$ and the lack of family history of diabetes $(p=0.63)$.

Intervention was found to be the most important factor $(R$-square $=0.25 ; p=0.031)$ in preventing gestational hypertension, after adjustment for age $\leq 35$ years $(p=0.18)$, the lack of family history of hypertension $(p=0.55)$ and $\mathrm{BMI} \leq 30(p=0.99)$.

Both gestational age at delivery (Controls: $261 \pm 22$, Therapeutic Lifestyle Changes: $279 \pm 6$ days, $p<0.001)$ and birth weight (Controls: $3010 \pm 715$, Therapeutic Lifestyle Changes: $3498 \pm 342 \mathrm{~g}, p$ : 0.001) were lower in the Controls, in agreement with the higher rate of preterm delivery.

The rate of caesarean delivery (Controls: 32.1\%, Therapeutic Lifestyle Changes: $33.1 \%$ ) or the inductions of

Table 2. Outcomes of pregnancy in the TLC and control groups.

\begin{tabular}{lccc}
\hline & $\begin{array}{c}\text { TLC } \\
\text { group (33) }\end{array}$ & $\begin{array}{c}\text { Control } \\
\text { group (28) }\end{array}$ & $p$ value \\
\hline GWG at delivery: & $8.8 \pm 6.5^{*}$ & $10.4 \pm 5.0$ & NS \\
- BMI 25-29.9 kg/m & $11.3 \pm 7.8$ & $11.3 \pm 3.0$ & NS \\
- BMI > 30 kg/m & $6.7 \pm 4.3$ & $10.1 \pm 5.6$ & 0.047 \\
GWG within IOM recommendation: & $22(66.7 \%)^{* *}$ & $11(39.2 \%)$ & 0.032 \\
- BMI 25-29.9 kg/m 2 & $8(53.3 \%)$ & $5(62.5 \%)$ & NS \\
- BMI > 30 kg/m $/ \mathrm{m}^{2}$ & $14(77.8 \%)$ & $6(30.0 \%)$ & 0.003 \\
GDM diagnosis (24th-28th week) & $7(23.3 \%)$ & $16(57.1 \%)$ & 0.009 \\
Pregnancy-induced hypertension & $1(3.0 \%)$ & $7(25.0 \%)$ & 0.011 \\
Preterm delivery & 0 & $10(35.7 \%)$ & 0.002 \\
\hline
\end{tabular}

*Values are expressed as the mean $\pm \mathrm{SD}$. **Numbers with $\%$ in parenthesis.

Table 1. Socio-demographic features of the participants.

\begin{tabular}{|c|c|c|c|}
\hline & TLC group (33) & Control group (30) & $p$ value \\
\hline Age (years) & $\begin{array}{l}31.5 \pm 4.2^{*} \\
\text { (range } 25-42 \text { ) }\end{array}$ & $\begin{array}{l}32.4 \pm 5.9 \\
\text { (range } 23-44 \text { ) }\end{array}$ & 0.48 \\
\hline Ethnicity & $\begin{array}{l}\text { Caucasian: } 28(84.9 \%)^{* *} \\
\text { Maghreb: } 4(12.1 \%) \\
\text { Others: } 1(3.0 \%)\end{array}$ & $\begin{array}{l}\text { Caucasian: } 20(66.7 \%) \\
\text { Maghreb: } 6(20.0 \%) \\
\text { Others: } 4(13.3 \%)\end{array}$ & 0.14 \\
\hline Education & $\begin{array}{l}\text { Low-Middle school: } 11(33.3 \%) \\
\text { High school: } 22(66.7 \%)\end{array}$ & $\begin{array}{l}\text { Low-Middle school: } 13(43.3 \%) \\
\text { High school: } 17(56.7 \%)\end{array}$ & 0.15 \\
\hline Job & $\begin{array}{l}\text { Housewife: } 7(21.2 \%) \\
\text { Handiwork: } 12(36.4 \%) \\
\text { Sedentary work: } 14(42.4 \%)\end{array}$ & $\begin{array}{l}\text { Housewife: } 11(36.7 \%) \\
\text { Handiwork: } 9(30.0 \%) \\
\text { Sedentary work: } 10(33.3 \%)\end{array}$ & 0.29 \\
\hline Nulliparity & $13(39.4 \%)$ & $13(43.3 \%)$ & 0.94 \\
\hline $\mathrm{BMI}($ mean $\pm \mathrm{SD})$ & $\begin{array}{l}32.1 \pm 5 \\
(\text { range } 25.1-45.2)\end{array}$ & $\begin{array}{l}32.9 \pm 6.2 \\
\text { (range } 25.0-45.5)\end{array}$ & 0.56 \\
\hline BMI categories & $\begin{array}{l}\text { BMI 25-29.9: } 15(45.5 \%) \\
\text { BMI } \geq 30: 18(54.5 \%)\end{array}$ & $\begin{array}{l}\text { BMI 25-29.9: } 10(33.3 \%) \\
\text { BMI } \geq 30: 20(66.7 \%)\end{array}$ & 0.18 \\
\hline
\end{tabular}

*Values are expressed as the mean $\pm \mathrm{SD}$. **Numbers with $\%$ in parenthesis. No differences between groups were found. 
labor (Controls: 18.6\%, Therapeutic Lifestyle Changes: $18.1 \%$ ) was equally distributed among groups.

No statistically significant differences were found in maternal morbidity (post-partum hemorrhage and/or perineal tears) at delivery. The number of large for gestational age babies was similar between the groups. Low 5-min Apgar, resuscitation and Neonatal Intensive Care Unit admission were equally distributed among groups.

Significant changes in eating habits occurred in the Therapeutic Lifestyle Changes group, increasing the number of snacks/day, the consumption of vegetables and fruits. Moreover, intervention also decreased the consumption of sugar. No differences in the number of daily spoons of oil, red meat and complex carbohydrates intake were found. None of the women randomized to Therapeutic Lifestyle Changes group presented a detectable ketonuria during pregnancy.

The step numbers for each walking session was constant during pregnancy $(3267 \pm 1683$ at 36th week and $3755 \pm 1816$ at 28 th week).

\section{Discussion}

We developed a behavioral intervention to promote a healthier lifestyle in women with pre-pregnancy $B M I \geq 25 \mathrm{~kg} / \mathrm{m}^{2}$. The program was effective in reducing gestational weight gain in obese women and, as a consequence, the most of them remained within IOM-recommended ranges [7]. On the contrary, intervention was unable to modify gestational weight gain in overweight women. Perhaps, such women were less motivated to adhere to the program.

Obesity in general population is characterized by an enhanced visceral adipose tissue (able to regulate several pro-inflammatory substances) decreasing glucose uptake and increasing insulin resistance, thus leading to gestational diabetes mellitus, endothelial dysfunction, hypertensive disorders and preterm delivery. This mechanism could explain why obese women randomized to Control group reported a higher rate of the above negative outcomes.

Several types of interventions have been proposed to limit gestational weight gain [12]. Only some of them demonstrated efficacy in high-risk populations. Probably, this is due to several factors, including the heterogeneity of the study populations, the lack of exercise associated with a dietary intervention, the diverse approaches to control gestational weight gain and the timing of recruitment.

Based on the variety of the types of interventions as well as the outcomes reported among studies, the authors of the last Cochrane review [12] concluded that currently there is no enough evidence to recommend any intervention to prevent excessive weight gain during pregnancy. However, our data suggest that consistent physical activity added to a caloric restriction in obese pregnant women can prevent excessive weight gain reducing the related unfavorable outcomes. Unexpected, the rate of gestational diabetes mellitus in Controls is high, however, a logistic regression analysis confirmed the Therapeutic Lifestyle Changes diet was an independent factor for preventing gestational diabetes mellitus after adjusting for other risk factors. Moreover, other authors [22] reported a similar prevalence in pregnant Controls.
The efficacy of our intervention is supported by the significant changes occurring in eating behaviors.

Although the lower gestational weight gain was associated with a lower incidence of gestational diabetes mellitus and/or hypertensive disorders, neonatal health was not improved and the incidence of macrosomic babies remained unaffected. Similar data have been reported in previous intervention trials [22-27]. This may be a result of the small number of patients included in our study and thus the very small number of neonates requiring intensive care.

A systematic review on exercise effects for preventing gestational diabetes mellitus [28] did not report positive results. In our study, however, consistent mild physical activity along with caloric restriction reduces the gestational diabetes mellitus diagnosis. An important confounding factor in prescription of behavioral changes is the adherence to the program. Indeed, just recently a systematic review about this issue has been published [29]. In many studies, follow-up is not rigorous [12]. In our program, monitoring through diet evaluation as well as early pregnancy counseling by a dietitian helped the participants to better adhere to Therapeutic Lifestyle Changes program.

In conclusion, a multilevel intervention including caloric restriction changes in eating behavior and consistent physical activity was able to reduce gestational weight gain in obese women, as well as the related pregnancy complications.

\section{Declaration of interest}

The authors report no conflict of interest.

\section{References}

1. Organisation for Economic Co-operation and Development. Health at a glance: Europe. 2010. http://ec.europa.eu/health/reports/docs/ health_glance_en.pdf.

2. Leddy MA, Power ML, Schulkin J. The impact of maternal obesity on maternal and fetal health. Rev Obstet Gynecol 2008;1: $170-8$.

3. Hedderson MM, Weiss NS, Sacks DA, et al. Pregnancy weight gain and risk of neonatal complications: macrosomia, hypoglycemia, and hyperbilirubinemia. Obstet Gynecol 2006;108: 1153-61.

4. Cedergren M. Effects of gestational weight gain and body mass index on obstetric outcome in Sweden. Int J Gynaecol Obstet 2006; 93:269-74.

5. Stotland NE, Cheng YW, Hopkins LM, Caughey AB. Gestational weight gain and adverse neonatal outcome among term infants. Obstet Gynecol 2006;108:635-43.

6. Stuebe AM, Landon MB, Lai Y, et al. Maternal BMI, glucose tolerance, and adverse pregnancy outcomes. Am J Obstet Gynecol 2012;207:62.

7. Institute of Medicine (US) and National Research Council (US) Committee to Reexamine IOM Pregnancy Weight Guidelines; Rasmussen KM, Yaktine AL, editors. Weight Gain During Pregnancy: Reexamining the Guidelines. Washington (DC): National Academies Press (US); 2009. PubMed PMID: 20669500. Page 148-151.

8. American College of Obstetrics and Gynecology. Committee opinion number 267: Exercise during pregnancy and the postpartum period. Obstet Gynecol 2002;99:171-3.

9. American College of Sports Medicine. Impact of physical activity during pregnancy and postpartum on chronic disease risk: roundtable consensus statement. Med Sci Sports Exerc 2006;38: 989-1006.

10. Abrams B, Altman SL, Pickett KE. Pregnancy weight gain: still controversial. Am J Clin Nutr 2000;71:1233S-41S. 
11. Carmichael S, Abrams B, Selvin S. The pattern of maternal weight gain in women with good pregnancy outcomes. Am J Public Health 1997;87:1984-8.

12. Muktabhant B, Lumbiganon $\mathrm{P}$, Ngamjarus $\mathrm{C}$, Dowswell $\mathrm{T}$. Interventions for preventing excessive weight gain during pregnancy. Cochrane Database Syst Rev 2012;4:CD007145.

13. American Diabetes Association. Standards of medical care in diabetes-2011. Diabetes Care 2011;34:S11-61.

14. Bohlscheid-Thomas S, Hoting I, Boeing $\mathrm{H}$, Wahrendorf $\mathrm{J}$. Reproducibility and relative validity of food group intake in a food frequency questionnaire developed for the German part of the EPIC project. Int J Epidemiol 1997;26:S59-70.

15. Bohlscheid-Thomas S, Hoting I, Boeing $\mathrm{H}$, Wahrendorf $\mathrm{J}$. Reproducibility and relative validity of energy and macronutrient intake of a food frequency questionnaire developed for the German part of the EPIC project. Int J Epidemiol 1997;26:S71-81.

16. Boeing $\mathrm{H}$, Bohlscheidt-Thomas $\mathrm{S}$, Voss $\mathrm{S}$, et al. The relative validity of vitamin intakes derived from a food frequency questionnaire compared to 24-hr-recalls and biological measurements. Results from the EPIC pilot study in Germany. Int J Epidemiol 1997;26:S82-90.

17. Hypertension in pregnancy: the management of hypertensive disorders during pregnancy. NICE Clinical Guidelines, No. 107 National Collaborating Centre for Women's and Children's Health (UK).

18. Recommended Levels Intake of Energy and Nutrients for the Italian Population, LARN (Livelli di Assunzione Raccomandati di Energia e di Nutrienti per la Popolazione Italiana), ed EDRA, Medical Publishing \& New Media, review 2012.

19. 'Istituto Superiore di Sanità,' Linee Guida per la gravidanza fisiologica 2011. Available from: http://www.snlg-iss.it/cms/files/ LG_Gravidanza.pdf

20. Mello G, Ottanelli S, Buti G. Nutrizione e gravidanza. In: Binetti P, Marcelli M, Baisi R, eds. Nutrizione individuo popolazione. Ott: Seu Roma Editore; 2009:601-20.
21. S.I.N.U (Società Italiana di Nutrizione Umana). Livelli di Assunzione Raccomandati di Energia e Nutrienti per la Popolazione Italiana - LARN revisione; 1996;85-6.

22. Matarrelli B, Vitacolonna E, D'angelo M, et al. Effect of dietary myo-inositol supplementation in pregnancy on the incidence of maternal gestational diabetes mellitus and fetal outcomes: a randomized controlled trial. J Matern Fetal Neonatal Med 2013; 26:967-72.

23. Quinlivan JA, Lam LT, Fisher J. A randomised trial of a four-step multidisciplinary approach to the antenatal care of obese pregnant women. Aust N Z J Obstet Gynaecol 2011;51: 141-6.

24. Phelan S, Phipps MG, Abrams B, et al. Randomized trial of a behavioral intervention to prevent excessive gestational weight gain: the Fit for Delivery Study. Am J Clin Nutr 2011;93:772-9.

25. Polley BA, Wing RR, Sims CJ. Randomized controlled trial to prevent excessive weight gain in pregnant women. Int J Obes Relat Metab Disord 2002;26:1494-502.

26. Luoto R, Kinnunen TI, Aittasalo M, et al. Primary prevention of gestational diabetes mellitus and large-for-gestational-age newborns by lifestyle counseling: a cluster-randomized controlled trial. PLoS Med 2011;8:e1001036.

27. Guelinckx I, Devlieger R, Mullie P, Vansant G. Effect of lifestyle intervention on dietary habits, physical activity, and gestational weight gain in obese pregnant women: a randomized controlled trial. Am J Clin Nutr 2010;91:373-80.

28. Han S, Middleton P, Crowther CA. Exercise for pregnant women for preventing gestational diabetes mellitus. Cochrane Database Syst Rev 2012;7:CD009021.

29. Currie S, Sinclair M, Murphy MH, et al. Reducing the decline in physical activity during pregnancy: a systematic review of behaviour change interventions. PLoS One. 2013 Jun 14;8(6):e66385. doi: 10.1371/journal.pone.0066385. Print 2013. 